\title{
Implications of climate change for expanding cities worldwide
}

Article

Published Version

Hunt, J. C., Timoshkina, Y. V., Bohnenstengel, S. I. and Belcher, S. (2013) Implications of climate change for expanding cities worldwide. Proceedings of the ICE - Urban Design and Planning, 166 (4). 241 -254. ISSN 1755-0807 doi: https://doi.org/10.1680/udap.10.00062 Available at https://centaur.reading.ac.uk/28480/

It is advisable to refer to the publisher's version if you intend to cite from the work. See Guidance on citing.

To link to this article DOI: http://dx.doi.org/10.1680/udap.10.00062

Publisher: ICE

All outputs in CentAUR are protected by Intellectual Property Rights law, including copyright law. Copyright and IPR is retained by the creators or other copyright holders. Terms and conditions for use of this material are defined in the End User Agreement.

\section{www.reading.ac.uk/centaur}

\section{CentAUR}

Central Archive at the University of Reading 
Reading's research outputs online 


\section{Implications of climate change for expanding cities world wide}

1 Julian C. Hunt CB, MA, DPhil, FIMA, FRS Emeritus Professor of Climate Modelling, Department of Earth Sciences, University College London, UK

2 Yulia V. Timoshkina MPhil, DPhil

Honorary Research Fellow, Department of Mathematics, University College London, UK
3 Sylvia I. Bohnenstengel Dipl-Met Research Fellow, Department of Meteorology, University of Reading, UK

4 Stephen Belcher MA, DPhil Joint Met Office Chair in Weather Systems, Department of Meteorology, University of Reading, UK
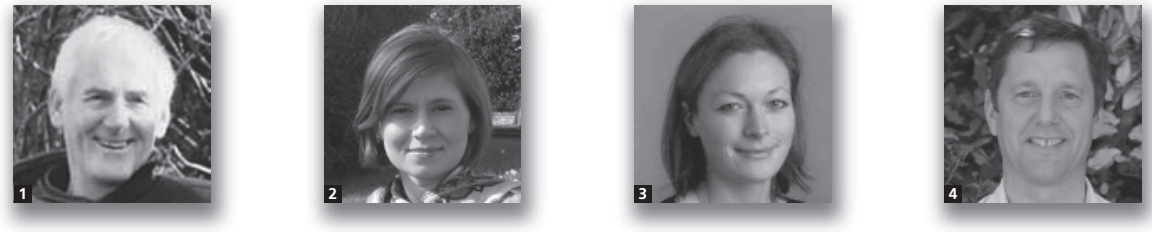

This paper analyses the trends of the changing environmental effects within growing megacities as their diameters exceed 50-100 km and their populations rise beyond 30 million people. The authors consider how these effects are influenced by climate change, to which urban areas themselves contribute, caused by their increasing greenhouse gas emissions associated with rapidly expanding energy use. Other environmental and social factors are assessed, quantitatively and qualitatively, using detailed modelling of urban mesoscale meteorology, which shows how these factors can lead to large conurbations becoming more vulnerable to climatic and environmental hazards. The paper discusses the likely changes in meteorological and hydrological hazards in urban areas, both as the climate changes and the sizes of urban areas grow. Examples are given of how these risks are being reduced through innovations in warning and response systems, planning and infrastructure design, which should include refuges against extreme natural disasters. Policies are shown to be more effective when they are integrated and based on substantial community involvement. Some conclusions are drawn regarding how policies for the natural and artificial environment and for reducing many kinds of climate and hazard risk are related to future designs and planning of infrastructure and open spaces.

\section{Climate and environment of urban areas}

\subsection{Sustainability}

In the twentieth century, the numbers of both large cities and megacities have been increasing; the quantity almost tripled between 1950 and 1975 (from eight to 22), and nearly doubled from 1975 to 2000 (to 39), and is expected to grow by about half again in the short period between 2000 and 2015 (UN, 2001). As the proportion of the world population living in urban settlements rises progressively during this century from $50 \%$ to about $60-70 \%$ (UN Population Division, 2006), their energy demands lead to an ever greater proportion of the world's greenhouse gas (GHG) emissions.

Since the second United Nations (UN) habitat conference in 1996 (Hunt, 1996; UN, 1996), politicians, as well as environmental scientists, meteorologists and urban planners, have begun to realise that the objectives of sustainability, set out in the UN Brundtland report (Brundtland, 1987), could only be achieved by understanding and dealing effectively with the interactions between cities and the wider regional and global environment (Hunt et al., 2007; Lee, 2007; Rosenzweig and Solecki, 2010).

The consumption of energy and material resources, and the contributions to GHG emissions in cities are rising, but not as fast as per person for the population as a whole (Hunt, 2005; Rosenzweig et al., 2010). This is because in cities with public transport and with high density and low-energy-use housing, such as New York and London, people generally use less energy per person than in rural or suburban areas. This difference is increasing as the energy used per person for transportation grows proportionately with the size of lowdensity suburban areas. 
However, the high concentration of people per square metre in urban areas, about 100-1000 times the global average, also affects their ultimate sustainability because it can make their populations more vulnerable to extreme natural hazards. Some of these hazards will be further exacerbated directly or indirectly by human-induced climatic and environmental change. Ensuring sustainability of urban settlements requires studying how both short- and long-term measures to improve their resilience against natural and other disasters need to be modified to allow for their growing size and the interactions with changes to the regional climate and to the terrestrial, atmospheric and aqueous environments.

In industrial countries, these dangers have been reduced by improvements in the science and technology of hazard forecasting, in disaster management and in preventative design. Fewer lives have been lost and much less physical damage caused by hazards in major cities in developed compared with developing countries. However, the heat waves and floods in Europe and the USA in past decades have shown that all societies can be vulnerable to hazards if they are large enough, which can sometimes be so unexpected that even the insurance industry may have overlooked them (Kalkstein and Sheridan, 2007). The nature and frequency of extreme hazards are changing, which lead to greater impacts on communities and infrastructure. New risks are arising associated with large cities and with the movements and reactions of people in emergencies. These risks are affected by changes by local meteorology and hydrology and these relate to changes in regional climate and in land surface cover such as desertification (Hunt 2005, 2009a; Kintisch, 2005).

\subsection{Changes in global and regional climate and environment}

During the UN summit in Mexico in January 2011, the latest projections of GHG emissions were discussed, based on likely estimates of expanding, rather than contracting emissions of GHG by developed and developing countries, which indicate that the future rise in average global temperature by the end of the century will lie between 3 and $4^{\circ} \mathrm{C}$, which is significantly greater than the $2^{\circ} \mathrm{C}$ discussed at the UN climate conference in Copenhagen in 2010 (e.g. Tyndall Centre for Climate Change Research, 2010). This will hasten and amplify the impacts of climate change to a greater extent than many current plans allow for. But it is essential to recognise that the shift in the mean temperature is likely to increase the variability of weather and seasonal climate in certain parts of the world. Extremes of high and low temperature, and drought and flood, are being recorded around the world.

As changes to the global environment and climate bring greater and wider threats to societies and the natural world, the objective of sustainable development for cities becomes even more essential, but requires reinterpreting (e.g. Schellnhuber et al., 2004). The scientific study of trends of changing climate needs to combine meteorological and environmental research for urban areas and their interactions on regional and global scales (Bornstein, 1987; Fernando, 2008; Fernando et al., 2001; Gayev and Hunt, 2007; Head, 2008). The effects of climate change, seasonal variability and extreme natural hazards have to be considered (Hunt et al., 2007; Pachauri and Reisinger, 2007a).

For the study of urban areas in present climatic conditions, calculations can be based on local observational data, but for predicting future trends they are determined by the prediction of global climate models.

Mesoscale meteorological models used to study the climate and environment within specific local areas also depend on the influence of the weather, environment and climate outside the areas, that is 'boundary conditions' (Porson et al., 2009). Since climatic and environmental changes are strongly influenced by local topography and by marked variations in the local surface conditions, including those produced artificially, mesoscale models need to be sufficiently detailed to describe these local factors. Such models have demonstrated in a number of cases how trends in average synoptic scale flows can interact with the special topographic and surface features so as to induce large regional effects. In polar regions, climatic changes have caused a deflection of the zonal flow, so that the mean temperature has risen by $3 \mathrm{~K}$ over the past 50 years - more than triple the global average (Orr et al., 2008). Downscaling results have been more successful in modelling variations in some regional climatic trends, for example in temperature and wind, than in others, for example precipitation (Boé et al., 2009; Cassou and Terray, 2005; Smith et al., 2006). Observational studies of the decadal warming trend in cities worldwide show that they are greater than in the surrounding regions: in central London the urban heat island effect currently adds up to a further $5-6^{\circ} \mathrm{C}$ to summer night temperatures and will intensify in the future (London Climate Change Partnership, 2002). The build-up of heat (and pollution) in the boundary layer below $200-300 \mathrm{~m}$ is now being monitored and studied as urban areas develop (e.g. Barlow et al., 2011; Mathias et al., 2002).

Considering possible future risks requires first identifying and estimating the full range of possible hazard scenarios. In builtup areas, there are a number of critical environmental conditions which lead to primary and/or secondary dangerous impacts on the physical and social structure such as flooding, causing secondary effects of water pollution and cuts of electrical power (see Table 1). Government and communities need to understand these different events individually and collectively in order to decide on long-term polices and shortterm response. Precautionary measures may avert the necessity for drastic actions later, such as cities being abandoned as they have been in past climates, for example Mohenjo-daro in 


\section{Causes}

Primary hazards

Changing impacts over time from climate/environmental changes

Wind (speed $U \uparrow$ )

$\left(I_{0}+\Delta /\right) \uparrow\left(\right.$ see note $\left.{ }^{a}\right)$

Flood (water level $h \uparrow$ ).

$\left(I_{0}+\Delta /\right) \uparrow$

Causes:

(a) local precipitation

(b) high river flow/high

coastal winds/tides/cyclones

Heat $(T \uparrow)$

$\left(I_{0}+\Delta I\right) \uparrow\left(\right.$ see note $\left.{ }^{\mathrm{a}}\right)$

Pollution $(C \uparrow)$

$I_{0}+\Delta I \uparrow$,

Secondary and geophysical hazards

Physical/environmental $\quad\left(I_{0}+\Delta /\right) \uparrow\left(\right.$ see note $\left.{ }^{a}\right)$

effects

Societal/economic

loss of capacity

$\left(I_{0}+\Delta /\right)\left(\right.$ see note $\left.{ }^{a}\right)$

$\bar{I} \uparrow(?)$

Conclusion

$\overline{<\Delta />} \uparrow$ or $\downarrow$ (see note ${ }^{a}$ )
Changing impacts of increasing scale of urbanisation $L$ (in relation to scales $L_{H}$ of hazards and $L_{R}$ of meso-meteorology)

$\frac{L}{L_{\mathrm{H}}} \uparrow ; \frac{L}{L_{\mathrm{R}}} \uparrow$

$\Delta \hat{U} \uparrow \Delta \hat{I} \uparrow\left(\right.$ see note $\left.{ }^{\mathrm{b}}\right)$

As $\frac{L}{L_{\mathrm{H}}} \uparrow,<\Delta />\uparrow$

(a) $\frac{L}{L_{\mathrm{H}}}>1 \Rightarrow<\Delta />\downarrow$

(b) $\frac{L}{L_{\mathrm{H}}} \sim 1 \Rightarrow<\Delta />\uparrow$

$\frac{L}{L_{\mathrm{H}}} \sim 1-->\Delta T \uparrow$

$\Rightarrow \Delta \hat{I} \uparrow,<\Delta I>\uparrow$

$L / H \sim L \Rightarrow \Delta C$ I

$\Delta \hat{I} \uparrow,<\Delta I>\uparrow$

$\frac{L}{L_{\mathrm{H}}} \uparrow \Rightarrow<\Delta />\downarrow$ (see note ${ }^{\mathrm{a}}$ )

If $L / H I \Rightarrow \Delta \hat{I} \uparrow \quad\left(\right.$ see note $\left.{ }^{a}\right)$

(a) if $\frac{L}{L_{\mathrm{H}}} \uparrow \Rightarrow<\Delta />\downarrow$ (see note ${ }^{\mathrm{a}}$ )

(b) if $\frac{L}{L_{\mathrm{H}}}<1,<\Delta I>\uparrow$ (see note $^{\mathrm{b}}$ )

Note: $\uparrow$ implies increasing; $\downarrow$ implies decreasing trends; (?) means uncertain; $>$ means greater than; $<$ means less than.

a $=I_{\mathrm{CR}}$ for $H>H_{\mathrm{CR}} ;$ but $I \approx 0$ for $H<H_{\mathrm{CR}}$, the critical hazard threshold.

${ }^{\mathrm{b}} \Delta \hat{I}$ is peak impact; $\bar{I}$ is time average over many events; $\langle\Delta I\rangle$ is spatial average over urban area

Table 1. Changing impacts on cities of climate and environmental change and increasing scale of urbanisation.

Pakistan, which was destroyed and rebuilt seven times. Indeed some coastal communities and island states, such as the Maldives, are preparing for the same fate during this century as the sea level rises. In Britain this has been happening for 300 years; the post Ice Age sinking land levels led to the loss of Ravensburgh on the Yorkshire coast. Further coastal erosion and inundation along the east coast of England with localised defences is now accepted policy (Flood and Water Management Act, 2010). By contrast, the Netherlands, with a shorter coastline and different geological conditions, is able to raise coastal defences to prevent any loss of land (Netherlands government, 2007).

\subsection{Policy approaches}

The international community and some regions and cities around the world are beginning to act on the causes of climate change through technological development and by changing policies for future energy use and transportation so as to limit GHG emissions (as in EU countries) or at least to limit their rate of increase as in China (Hunt, 2009b). These developments also contribute to the other important policy objectives of reducing reliance on fossil fuels and improving energy security. But the necessary policies are not being introduced fast enough or strongly enough to stabilise the world climate.

Given the current projections of global warming and its impacts, governments and cities are therefore also introducing policies to enable communities, industries and agriculture to withstand the likely consequences of climate change (Parry et al., 2007b). The global costs of adaptation to climate change if introduced soon could be less than 1-3\% of global economic activity (Stern, 2007). 
The Netherlands government, following a major review of the country's risks, plans to raise its dykes to allow for the eventual rise in sea level of several metres (Kabat et al., 2009), corresponding to the worst-case scenario of melting of polar ice-caps (Hunt, 2009a). German measures in 2005 were described by Hunt et al. (2007). UK measures were reviewed by the adaptation sub-committee of the Committee on Climate Change (CCC, 2010), when it was shown that little progress has been made so far to avert significant societal disruptions caused by long-term climate change.

There are common elements and concepts in the main technical, economic and administrative policies for dealing with climatic and environmental risks (e.g. in infrastructure and operational risk management). Connecting and, in some cases, integrating these policies is practical but also more effective socially and economically (Parker and PenningRowsell, 2005). This approach also contributes to measures for long-term sustainability (for example introducing renewable or high-efficiency energy systems in new housing developments), as some cities and regions have demonstrated already. The environmental advantages and implications for reducing climatic and environmental hazards in urban areas through connected policies are discussed in Section 3 - see Table 2.

\section{Climate change, environmental risks and urbanisation}

\subsection{Factors contributing to risks}

The main types of meteorological, hydrological, or environmental hazard (see Table 1) that cause damaging impacts on communities are the following: high wind speeds $(U)$; raised water levels $(h)$ caused by local precipitation, river discharges or wind-induced surges and waves along coasts; high temperatures $(T)$ associated with regional meteorology and artificial effects produced by changes in surface properties and heat emissions from energy systems; high concentrations $(C)$ of atmospheric gases and particulates arising from natural sources (e.g. windblown sand or noxious gases from lakes) and from artificial processes of industry, transport and agriculture, and so on. All kinds of hazards (denoted generically by $H$ ) impact on the physical and societal structure of communities, with long-term damaging effects on their physical infrastructure, health, and social and economic capacities. But the magnitude of the impact (denoted by $I$ ) depends on $H$, and also how well all these aspects of the community are adapted to reduce the impact of the hazard and to recover afterwards; in other words its resilience or lack of vulnerability (Adger, 2006; Crichton, 2007; Hunt, 2009a; Hunt et al., 2007).

Some countries are also exposed to other kinds of equally damaging geophysical hazards such as volcanoes, earthquakes and tsunamis (Hunt and Kopec, 2011). These hazards are first associated with regional weather and climate and with environmental effects that are independent of any local urban effects (even though urban areas worldwide are affecting the global climate). These non-urban impacts are denoted by $I_{0}$. Regional effects may be exacerbated by significant regional amplification of global warming mentioned above.

In urban areas the presence of a large population as well as certain physical, chemical and biological processes can lead to additional hazards and impacts. In other words, urban areas are particularly vulnerable to hazards denoted by $\Delta I$ (Adger, 2006). Estimating impact risks first requires considering which hazards can occur simultaneously, for example as can happen with high winds, floods and waves. But other combinations, such as high temperature and very high winds, may be very unlikely, depending on the climatic region and the geography. Second, in urban areas different hazards can combine to enhance $\Delta I$. This can occur with flooding and also when high urban temperatures worsen illnesses caused by high air pollution concentrations, which is documented in Africa (Acops, 2002) and Asia (HEI, 2004).

Climate change and urban factors can also exacerbate the impacts of geophysical hazards (Ravilious, 2010), for example longer lasting stagnant atmospheric conditions following volcanic eruptions, or where tsunami impacts on coastal cities will increase with sea level rise and may in future occur on arctic coasts as sea ice melts. Another possible geophysical hazard occurs in years of high solar activity, when ionisation of the atmosphere causes breakdown of the electrical systems that are essential for the infrastructure of cities - a concern for certain Asian cities during the next sun-spot cycle in about 2012 (Lam, personal communication, 2009). Some secondary hazards come from natural processes such as rain-induced mud slides in cities on mountain slopes, particularly following tropical cyclones. Other secondary hazards are environmental effects caused by the disruption of the cities' systems, such as overflow from drains leading to widespread water pollution (Ristenpart, 2003).

Medical, social and economic impacts are of increasing concern to policy makers, since they determine whether communities can recover before the next hazard event occurs. Failure to do so threatens their long-term viability (Hunt, 2009a) - see Table 1. Insurance companies now assess vulnerability risk as much in terms of the social capacity of communities as by physical impacts of extreme events and preventive measures that may have been taken (UNEPFI, 2009).

Multidisciplinary meteorological, environmental, engineering and social science studies are needed to estimate such hazards 


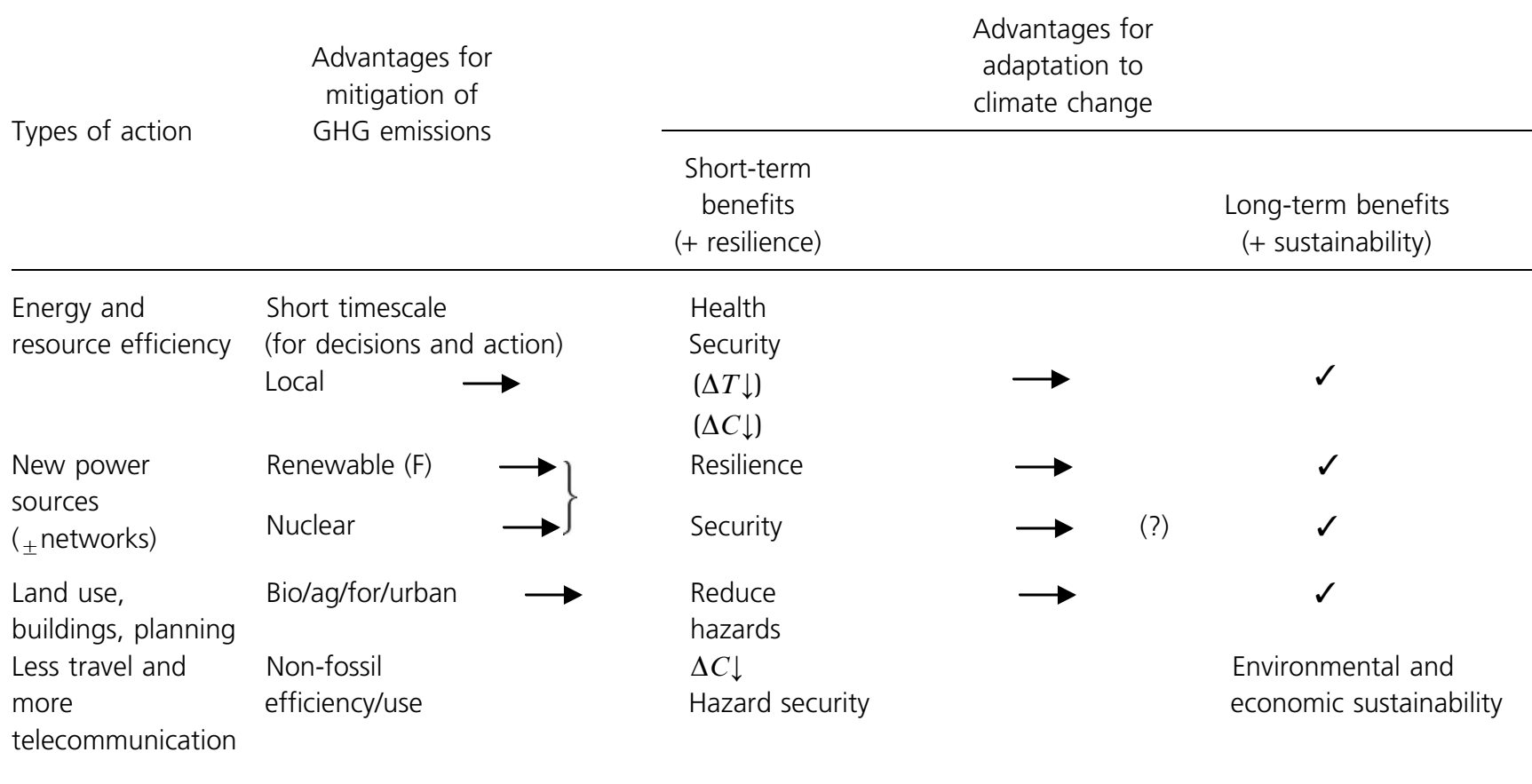

Notes:

(a) Actions for climate change also contribute to and link with resilience, resources, security, economics and social capacity (also affected by integration).

(b) Varying timescales for different actions.

(c) Continual information and warnings needed for all policy objectives.

(d) Response and recovery systems needed for all hazards - can be common for most cases.

(e) (?) means uncertain.

(f) Bio/ag/for/urban means appropriate low carbon forms of bio fuels, agriculture, forestry, bio mass, and urban design.

Table 2. Policies and actions for climate and environmental

hazards in urban areas: advantages for different objectives

and impacts, both separately and in combination, and as climatic and urban conditions change in the future. Comprehensive system models are now being constructed to include these features (see, for example, http://www.tyndall.ac. uk/images/People-and-Places). While numerical simulations of these physical and socio-economic models are required for quantitative predictions of a few cases, simplified modelling is also needed to provide interpolation, extrapolation and comparisons between ranges of simulation results. This approach enables estimates to be made of future trends, as in Table 1 and in the Appendix.

\subsection{Effects of increasing scale}

Note that estimates of trends for impacts from primary hazards are based on models of local meteorology and environmental processes, and on civil engineering studies of critical conditions in urban areas, particularly associated with high winds and floods. But estimates of secondary impacts also derive from system engineering concepts and societal models of resilience (e.g. Hunt, 2009a; Moser, 2007). Some impacts are only significant when the hazard exceeds a critical value, $H_{\text {cr }}$. As recent disasters have shown, this value depends on the strength of the precautions and engineering defences that were in place at the time. But for other hazards, such as higher temperatures caused by global warming and the urban heat island (Oke, 1978, 1982) and higher air pollution concentrations (e.g. Jacobson, 2002), adverse impacts $I$ on the well-being and environment of cities increase progressively as the hazard magnitudes $H$ increase, whether they occur separately or in combination. Recent analysis of future climate models suggests that the occasional blocking events associated with high temperatures will be more frequent, and may even last for 20 days, with very serious effects on the security of water resources over the whole European regions as well as in urban areas. Current data for summer periods are consistent with this trend (Cassou and Guilyardi, 2007).

An associated critical feature of the changing structure of the troposphere (Gaffen et al., 2000) is the lessening vertical stability and deepening and strengthening of convection (except over 
regions where this is limited by urban induced aerosols (Ramanathan et al., 2007)). This causes more intense rainfall events and flash flooding typically over scales of about $30 \mathrm{~km}$.

As the size of an urban area increases, its energy use and pollution emissions increase approximately in proportion to the area. In the evening and night time as the heat transferred to the air from the buildings is transported by the wind, the urban surface temperature increases in the downwind direction (Oke, 1978; also see Appendix). The peak concentration of air pollution also increases. Where tall buildings are close to each other the wind between them is less and they lose less heat to the sky by radiation. This is why the urban heat island is generally greater in American and East Asian cities than in European low-rise cities. Currently in East Asian cities clusters of tall buildings above $100 \mathrm{~m}$ high are being built separated by small gaps between them (less than $20 \mathrm{~m}$ ) leading to stagnant air over $24 \mathrm{~h}$. This is now also leading to increasing day-time temperatures as the convective eddies are prevented from ventilating the city streets (Zilitinkevich et al., 2006).

The length scale over which the urban heat island hazard is significant, denoted by $L_{\mathrm{H}}$, therefore grows broadly in proportion to the scale $L$ of expanding cities. But as the Paris heat wave of 2003 demonstrated, local variations in the urban environment temperatures are also very important, and can even determine the local pattern of mortality (CanouiPoitrine et al., 2006). In this case these hot spots effectively determined the average mortality impact per unit area over the city $\langle\Delta I\rangle$. This would be expected to increase as the urban temperature increases with the scale of cities.

As air pollutants are transported across the city, some gases increase in concentration, while others undergo chemical transformations. Some can even decrease in intensity. Overall, the scale of the pollutant hazard $L_{\mathrm{H}}$ increases with $L$, which will increase the impact on mortality of air pollution. In some countries air pollution concentrations are now large enough to cause a significant loss of visibility.

Unlike heat, which diffuses to the ground, pollutants can be advected far downwind of cities. In local sea-land breeze and valley circulations, as in Los Angeles and Phoenix, pollutants are transported $30 \mathrm{~km}$ out of the centre and are swept back to build up the concentrations even further (Fernando et al., 2001). Such local effects are limited to central areas of the cities but become less significant as they expand. Even low hills, such as those surrounding London and Athens, confine the airflow and pollutants at night and in stable conditions.

Where there are surrounding mountains higher than the depth of the boundary layer (about $1000 \mathrm{~m}$ ), they have a dominant role in the local meteorology and environment even in very large cities over $100 \mathrm{~km}$ in diameter, for example in Los Angeles or some cities in China (Lu et al., 2009).

Many observational and numerical studies (e.g. Bornstein, 1987), have shown how, over larger cities, the airflow, temperature profiles and precipitation patterns differ appreciably between those in the centre and those outside the urban areas. Recent measurements over central London (Barlow et al., 2011; Martin et al., 2009) show that the night-time depth of the mixed layer (about 200-300 m) is significantly greater than the shallow nocturnal layer (of less than $100 \mathrm{~m}$ ) in the surrounding rural areas (see Figures 1 and 2). As the new computations (detailed in the Appendix) show, the temperature profiles across urban areas vary in space and time even on flat terrain; they are even more complex where there are nearby hills (e.g. Brazel et al., 2005), coasts and local hot-spots such as airports. Over the neighbourhood scale of $1-3 \mathrm{~km}$ the temperatures are raised or lowered by parks, rivers, buildings and so on (Bohnenstengel et al., 2011). Because the surface temperature distribution also affects the wind profiles and turbulence (Owinoh et al., 2005), the near-surface air temperature does not simply vary in proportion to surface heating and cooling. As numerical simulations over London confirm (Bohnenstengel et al., 2011), this means that average urban temperatures are more effectively reduced by a distribution of smaller parks rather than a few large ones. An example of a large park (about $80 \mathrm{~km}^{2}$ ) to the south west of the centre of London and its lower surface temperature is shown in Figure 1.

Fluid dynamical studies of perturbed stratified flows with the Coriolis effects of the earth's rotation (Hunt et al., 2004; Rotunno, 1983) show that the changes in the direction and
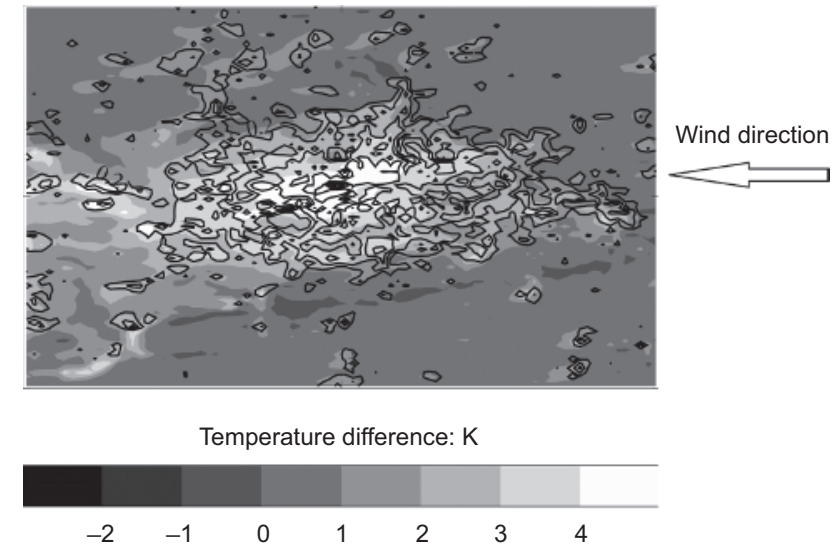

Figure 1. Different tonal shades show screen level temperature differences over London simulated at $23 \mathrm{~h}$ local time on 7 May 2008. Urban land-use fractions are depicted by black isolines 


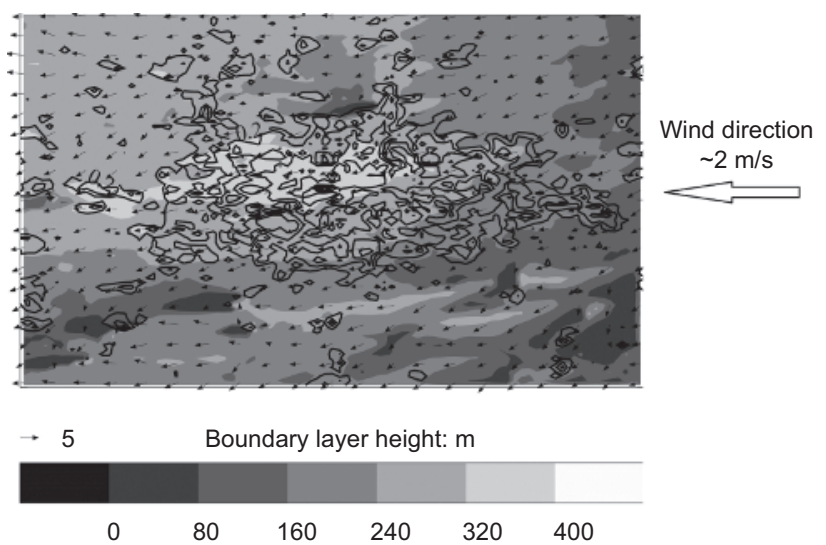

Figure 2. Boundary layer heights (different tonal shades) over London and $10 \mathrm{~m}$ wind vectors simulated at $23 \mathrm{~h}$ local time on 7 May 2008

speed of the airflow only become substantial when the length $L$ exceeds the 'Rossby radius' $\left\langle L_{\mathrm{R}}\right\rangle$, which is about $30 \mathrm{~km}$ at night and up to $100 \mathrm{~km}$ by day. This is the distance over which the urban area affects the boundary layer flow upwind and around the urban area (Collier, 2007). When $L$ is comparable to or exceeds $L_{\mathrm{R}}$, the airflow and patterns of precipitation downwind of large cities (or other areas of surface roughness like islands) are perturbed for distances larger than $L_{\mathrm{R}}$ (Orr et al., 2004). This distance $L_{\mathrm{R}}$ is also significant because it defines how the boundary depth $h$ varies at night in the city centre, where there is a greater surface heat flux.

The scale $L$ of 'mega' cities of the future will be comparable with or may even exceed $L_{\mathrm{R}}$. The characteristic wind patterns will change. Typically in the day time with a steady wind blowing towards the city, zones of increased wind speed form around the periphery and extend far downwind. These are also associated with areas of marked surface convergence and divergence, so that the patterns of precipitation change. But at night, when the approach wind is weaker, thermally induced wind in large cities can be greater (e.g. Plate, 1982). The significant consequences for urban climate and environment of cities when they reach this megascale is just beginning to be studied, for example in an European Union (EU) Megapoli project (see http://megapoli.dmi.dk/).

Another long-term hazard in growing urbanised areas in dry regions of the world is a reduced water supply, either caused by reduced precipitation locally or regionally or by depletion of the water table owing to overpumping of ground water. Water conservation and water harvesting (a growing practice in cities and rural areas of India) will have to be supplemented by desalination for coastal cities or water must be transported

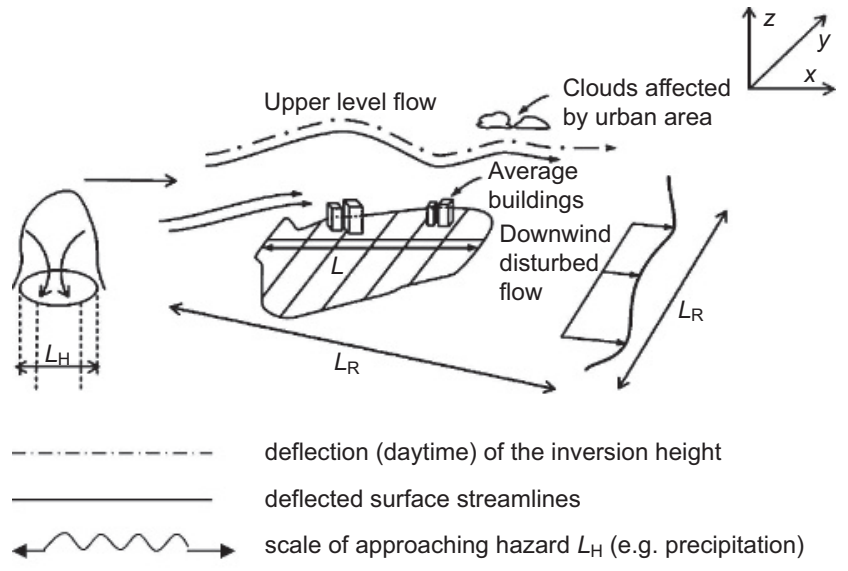

(a)

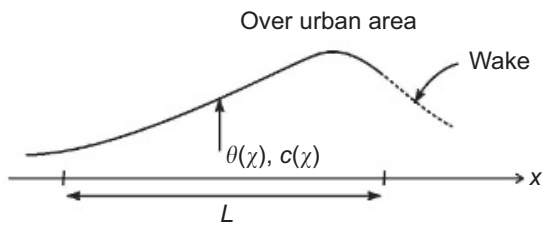

(b)

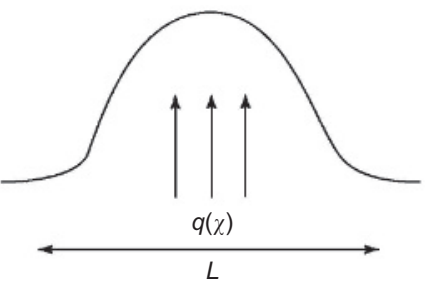

(c)

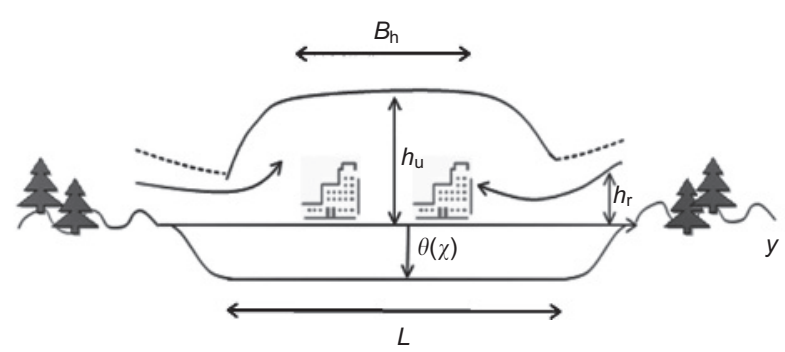

(d)

Figure 3. Some schematic features of the atmospheric environment of large cities. (a) Airflow patterns when the diameter $L$ becomes comparable with $L_{R}$ (the Rossby radius - deformation over which the flow is influenced upwind and in the wake downwind $\sim 30 \mathrm{~km}$ at night). (b) Typical asymmetrical variation of mean temperature $\theta(x)$ of non-reactive pollutant $c(x)$ when wind is from left to right (variation is quite different for reactive pollutants). (c) Typical vertical flux of mean temperature or pollutant. (d) Looking downwind (i.e. in $x$ direction) showing how at night the wind passes over the urban area and the surface urban temperature $\theta(x)$ is raised over the entire width $L$, but as the cool rural air moves inwards the width $B_{\mathrm{h}}$ is less than $L$. The boundary layer depth $h_{\mathrm{u}}$ is significantly greater than the rural boundary layer depth $h_{\mathrm{r}}$ (see Figures 1 and 2) 
over long distances (Fenner, 2009). The hydraulic energy requirement (per year) for long-distance water transport into cities (which for example is already a substantial fraction of California's energy use (Andrew, 2009)) grows more rapidly than for any other use, that is as $L^{6}$ (because it is proportional to $Q^{3}$, where $Q$ is the volume flow which increases with the population, which, in turn, varies as $L^{2}$ ). Figure 3 summarises features of the atmospheric environment of large cities schematically.

\subsection{Effects of scale on the functioning of urban areas} It is equally important to consider how the increasing scale of cities affects the operational, social and economic capacities to deal with hazards. Some hazards, both climatic and environmental, as well as those caused by industrial accidents and by malefactors, tend to be localised over hazard length scales $L_{\mathrm{H}}$, which generally do not depend on the overall size of the city $L$. But note that $L_{\mathrm{H}}$ increases with the magnitude of the hazard. In the largest cities $L$ generally exceeds $L_{\mathrm{H}}$ for mild and frequent hazards, such as precipitation or local wind storms, which provides these communities with relatively greater resilience. But in other cases the hazards extend across the city (where $L_{\mathrm{H}} \geqslant L$ ), either over the short term such as with fluvial flooding, large earthquakes, heat waves or tropical cyclones, or over days and weeks such as with heat waves or very large fluvial flooding. Then large cities can be dangerous because damage can spread (like water-borne or air-borne debris), and because people cannot leave the endangered areas of the city within the short period $T_{\mathrm{H}}$ of a short-term hazard warning, and may not be able to leave the city even in the event of long-term warning. These considerations should influence strategic policies about increasing the size of such cities and practical policies about managing them, including evacuation plans and investments in security measures, such as secure refuges for people above the level of any likely floods, and secure against the danger of flying debris in high winds (Brewick et al., 2009). Multidisciplinary modelling of these scenarios is an urgent research priority everywhere (Hunt, 2009a). The World Meteorological Organisation (WMO) has a special programme for a multi-hazards early warning system for Shanghai (Tang, 2009).

\section{Policies and actions}

Policies to deal with the impact of climate change and environmental hazards aim broadly to reduce their physical causes and to minimise their impact on society and the natural environment. The mitigation of $\mathrm{GHG}$ emissions associated with energy use in the largest urban areas could have a direct physical contribution to the global reduction efforts and should be economically feasible (Stern, 2007). Currently the trends in urban areas are upward (although not as much as the global average), which therefore threatens their own long-term sustainability and that of their surrounding region (Hunt, 2009a). But because of international trade, transportation and communications, these policies have international repercussions. For example, importing timber and reducing deforestation on mountain slopes has been an effective environmental and adaptation policy for reducing the danger of mud-slides associated with increased rainfall. But, as colleagues in Japan have pointed out, it sometimes impacts on the environment and causes mud-slide hazards in developing countries from where timber is exported. The UN earth summit declaration and biodiversity convention in Rio in 1992 provided the international framework for these policies and specifically committed governments to sustain the world's natural environment (UN, 1992). But some leading politicians and economists do not seem to understand this international commitment when they advocate climate change policies based only on minimising their 'opportunity' costs into the future (Hunt, 2008; Lawson, 2008).

Table 2 lists the main ways in which governments, communities and industry are working to implement the three main policy objectives of

(a) mitigating GHG emissions

(b) reducing the impacts of climatic and environmental hazards over the short and long term

(c) promoting sustainability.

For these measures to be successful, they also need to be widely accepted by the society. The security and stability of the communities and organisations will be at risk during periods of significant change, such as when people have to move or change their housing, change jobs, change their crops (e.g. to reduce water use (Fenner, 2009)) or, in the extreme case, leave their region or country. Systems for appropriate warnings about short-term hazards are essential for community security and confidence about future plans (which can be personalised through modern communications and computer translation into all local languages - as is done in India) (Hunt, 2009a). For organisations and communities to make these difficult longer-term transitions, there has to be extensive consultation and information for all the people involved, including pilot projects and demonstrations of new developments (Jones, 2004).

Most of the action areas that are listed in the table can contribute effectively to the three goals, but this is more likely to be achieved if at each stage there is some coordination between different policies and projects. However, such policy integration also requires public consultation that relates specific actions (e.g. one traffic scheme or one wind farm at a time) to wider sustainability criteria - as is proposed by the UK government in its recent UK Planning Act (2008), which 
establishes (quite controversially) an Infrastructure Planning Commission (see http://infrastructure.independent.gov.uk/)

Cities and urban communities recognise that their populations' energy requirements produce more than about $80 \%$ of the world's GHG emissions, and therefore they need to make substantial reductions in emissions. The compactness of cities and transport infrastructures facilitates the rapid introduction of non-carbon dioxide energy technologies for transport and buildings, which could reduce GHG emissions significantly the Greater London authority target is 60\% (from 1990 levels) by 2025 . As some communities have shown, the urban target could be more ambitious than $60 \%$ (CCC, 2009; Jones, 2004). Mitigation measures now being introduced for urban areas include improved buildings to reduce their energy use (and/or regulating it, as in Japan where much less air conditioning is now mandatory - see www.globeinternational.org) by reducing both heat loss and heat gain (with new materials, use of ventilation design and plant coverings), solar renewable energy, use of waste heat from power stations, non-fossil energy for transportation (e.g. hydrogen, electric cars and bikes) and efficient and non-polluting public transport. Measures to minimise energy in urban areas also contribute to the adaptation objectives of reducing urban heat island temperatures, as indeed pedestrians can experience in cities when they compare the radiated heat coming from older and from the latest 'green' buildings (Davies et al., 2008; Di Sabatino et al., 2009). Where mitigation measures involve efficient and non-fossil local energy sources, they also contribute to energy security, especially where communities introduce separate local power networks (Jones, 2004). Transportation measures can reduce air pollution, which with current technology is especially high along roads in large cities, where poorer people often live, with the resulting higher incidence of bronchial diseases (Hunt, 2009a). As cleaner transportation technology is introduced over the next 10 years, such as electric cars, there should be a net reduction in local pollution as well as reduced GHG emissions.

The integration of sustainability policies requires detailed planning of how separate measures interact beneficially. For example, developments in land use, building and planning, such as expanding parks and green spaces and expanding tree planting (at lower latitudes especially), can also contribute to the three policy objectives (see Table 2) and reduce hazards of high temperatures, flooding and concentrations of gaseous and particular substances. In south India the greening of some suburban areas has enhanced rainfall and has provided new, more secure and more sustainable sources of biomass for bioreactors. If very large urban areas are to be developed, not only must they be safe (as discussed above), but they should have significant green spaces to meet the adaptation objective of minimising urban heat island temperatures (Head, 2008). In
China foliage from universal tree planting together with animal and human waste is used as the biomass for community bioreactors replacing urban tree burning. A remarkably effective integration of measures in the Netherlands involves placing wind turbines on dykes along the coasts, so that the costs of adaptation to greater dangers of flooding are contributing to the costs of the foundations of the turbines. The UK government proposes electricity market reform to support and develop renewables and expand use of electric vehicles, which can help to expand the storage capacity for electricity to mitigate peak-time demand, and to reduce carbon dioxide emissions and air pollution (DECC, 2010). These and other integrated solutions require long-term planning and long-term commitment, which may not be consistent with deregulated markets for energy and real estate development and require government intervention.

\section{Conclusions}

This paper shows that as urban areas grow to an unprecedented scale in many parts of the world there are significant risks for their populations, which differ considerably depending on geographical and climatic factors. In general these can be greatly reduced through short- and long-term measures specific to these areas, both for protecting people and infrastructure. Developments in science, technology and institutional organisations are transforming warning and disaster response systems, through better understanding of the linkage between geophysical processes and detection technology and improving the education of communities that are particularly vulnerable to risk (Hunt and Kopec, 2011). The long-term threats to supplies of energy, food and water are growing as well, especially in developing countries, resulting from the effects of climate change, the depletion of local and regional resources (in particular water) and the deterioration of the local environment. Policies for urban areas will have to be reconsidered when these areas become so large that they adversely affect the local climate and environment, and add to natural risks, such as heat waves, flooding, extreme wind damage, air pollution events and so on, as explained in this paper. Their size will mean that people cannot escape in the event of extreme hazards, as recent hurricanes and tsunamis in the USA and Indonesia have shown. Indeed where attempts have been made to evacuate multimillion-sized populations, lives have actually been lost in the transport systems as they seized up. Communities have to understand and be prepared for risks of hazards and need to be involved in addressing them, in partnership with local and national government. Structural engineers, planners and social scientists need to consider more urgently the design of appropriate shelters in urban and also in rural areas. These need to be technically effective, but also socially acceptable to the communities which has not always been the case in certain developing countries, for example where preservation of livestock has been 
neglected in emergency measures. Estimates of the likelihood and impacts of extreme events in growing conurbations are needed to plan and justify the investment needed for these precautionary measures.

Urban communities are only likely to support policies leading to reduced GHG emissions and lowering risks associated with environmental and climatic change if they are fully informed and consulted about the most appropriate measures in the local context, such as the dependence on natural conditions, the planning of the city and the use of energy. For example in Texas urban dwellers fearful of tornadoes, cyclones or severe flooding are considering different infrastructure and planning policies for mitigation and adaptation, such as renewable energy, more efficient buildings, and hard and soft defences (e.g. shelters or landscaping). Citizens in high-density cities subject to floods, cyclones and earthquakes like Tokyo and Hong Kong, on the other hand, are focusing on improving the resilience of their systems for low-carbon dioxide energy and public transport and housing. The 20 largest cities in the world are sharing knowledge about their mitigation and adaptation policies (see www.c40cities.org). At the same time all urban areas need improved warning systems for weather and climate impacts both for short-term periods and, as science advances progressively, over longer periods. As communities are informed better about and also observe for themselves how their local climates and environment are changing, they will be more able to act on their own and to support local and national policies. The evidence from medium-sized communities in Europe (for example Woking, UK (Jones, 2004)) is that this is quite feasible. The question is whether in growing conurbations, there can be the same level of community and political involvement to meet the ever greater challenges of these regions.

This paper has shown some aspects of the complexity of establishing optimum policies for dealing with climate change in expanding urban areas. Since this and other research is indicating how the likely degree of future climate change impacts will require qualitative changes in the planning and operation of cities, depending on the area of the world concerned, environmental, engineering and societal research needs to address these problems more fully than is being done at present.

\section{Acknowledgements}

The authors' (JCRH, SB, SEB) work has been part of the London Urban Climate Network, 'Lucid' project, funded by the Engineering and Physical Sciences Research Council. JCRH also acknowledges support from Midi-Pyrenean Innovation as a visiting Pierre Fermat professor in Toulouse in 2007 and 2008; from the Centre for Environmental Fluid Dynamics at Arizona State University, and from the Natural
Environment Research Council (NERC) support to the Centre for Polar Observation and Modelling (CPOM) and EU support to the Global System Dynamics and Policy (GSDP) project at University College London. YT acknowledges support from Acops.

The authors are also grateful for conversations with J. P. Steadman, J. Fernando, S. Chun, V. Masson, C. Cassou, D. J. Carruthers, R. Bornstein, S. Sabatino and A. Kareem. An early version of this paper was presented at the American Meteorological Society meeting in Phoenix, Arizona in January 2009.

\section{Appendix}

Explanations to Figures 1 and 2: numerical simulation of the nocturnal urban heat island over London

The local, or 'meso', scale version of the 'unified' numerical weather prediction model of the UK Met Office has been specially modified for detailed study of urban areas. This is the new urban scheme 'Moruses' and the Met Office urban surface exchange scheme at the University of Reading (Harman and Belcher, 2006; Porson et al., 2009). For the simulation presented here it was run within for a 3-day simulation over London starting on 6 May 2008 at 18:00 $\mathrm{h}$ local time. This study is part of the 'Lucid' collaborative project (Mavrogianni et al., 2011).

The meteorological situation during these 3 days in May 2008 was dominated by a high-pressure system over Europe with low synoptic winds so that local temperature gradient, for example land-sea-urban, could determine the local meteorology situation over the UK. The simulation was run with a horizontal resolution of $1 \mathrm{~km} \times 1 \mathrm{~km}$ using nine 'types of surface' to model different types of the sub-grid scale land-use. Two of these tiles simulate the surface energy balance for urban street canyons separately from those for energy for urban roof level. The urban modelling was nested downwards within larger-scale simulations on a $12 \mathrm{~km}$ to a $4 \mathrm{~km}$ scale, which in turn was nested in a global simulation on a scale of $100 \mathrm{~km}$. The initial and boundary conditions were determined by the global simulation.

Figure 1 shows how the modelled changes in the urban-rural land surface affect the screen level temperatures (i.e. at $2 \mathrm{~m}$ ) over London at night time. The contours show the difference in the screen level temperatures between the urban areas (depicted by contour lines) and the rural areas surrounding London, where the surface was approximated modelled as grassland. A strong urban heat island develops with average urban-rural temperature difference of about $3 \mathrm{~K}$ and the peak value exceeding $5 \mathrm{~K}$ near the city centre of London. Note the sharp boundary between the rural and urban surface temperatures. The screen level temperatures respond locally to the fraction of the area that has an urban land surface, so that cooler temperatures are 
simulated over and down-wind of green areas, such as Richmond Park. This, as mentioned in Section 2, affects the local urban heat island temperature. It is clear that the centre of the urban heat island over London is slightly advected to the west, or the leeside of the centre of London. Downwind of London there is a well-defined thermal 'plume', but it shrinks in width as it mixes with the rural boundary layer (such as in Figure 3(d)).

Figure 2 shows the spatial pattern of the boundary layer depth over the London area. Over the central, most densely built-up areas the boundary layer reaches its maximum depth $(h)$ of 350$450 \mathrm{~m}$. This persists late into the night, while the rural surrounding areas show a thinner boundary layer depth of about 100-200 m. The buoyancy forces associated with the urban-rural temperature difference induce an airflow inwards, which is why the urban boundary layer depth $h_{\mathrm{u}}$ progressively reduces in the suburbs and also downwind of the urban area. Recent night-time measurements in London showed $h \approx 200 \mathrm{~m}$ (Barlow et al., 2011). The boundary layer is also affected by local changes in the surface land-use leading to lower boundary layer depths over park areas like Richmond Park. The simulations showed clearly that there is a nocturnal temperature increase near the ground over most of the urban area. But the airflow and its effects on the patterns of the transport of pollutants above the surface vary markedly over the urban area, which is important for operational models for urban weather forecasting (Clark et al., 2009) and for air pollution modelling (e.g. urban ADMS model - www.cerc.co.uk).

\section{REFERENCES}

Acops (2002) Report of conference on coastal zones of sub Saharan Africa. Proceedings of the Workshop on Coastal Zones in Sub-Saharan Africa. London. See http://archive. iwlearn.net/www.acops.org/ACOPS/images/gefprojects/ CoZSSA\%20Synopsis.pdf (accessed 20/01/2011).

Adger W (2006) Editorial: Resilience, vulnerability, and adaptation: a cross-cutting theme of the International Human Dimensions Programme on Global Environmental Change. Global Environmental Change 16(3): 268-281.

Andrew J (2009) Adapt, flee, or perish: Responses to climate change for California's water sector. Proceedings of the Ice, Snow and Water Workshop, San Diego. See http://esi.ucsd. edu/gwi/index.php?option $=$ com_content\&task $=$ view\& $\mathrm{id}=14 \&$ Itemid $=26$ (accessed 01/04/2010).

Barlow JF, Dunbar TM, Nemitz EG, et al. (2011) Boundary layer dynamics over London, UK as observed using Doppler Lidar during REPARTEE-II. Atmospheric Chemistry and Physics 11(5): 2111-2125.

Boé J, Terray L, Cassou C and Najac J (2009) Uncertainties in European summer precipitation changes: role of large scale circulation. Climate Dynamics 33(2-3): 256-276.

Bohnenstengel SI, Evans S, Clark P and Belcher SE (2011)
Simulations of the London urban heat island. Quarterly Journal of the Royal Meteorological Society 137(659): 1625-1640.

Bornstein R (1987) Mean diurnal circulation and thermodynamic evolution of urban boundary layers, modeling the urban boundary layer. Proceedings of the American Meteorological Society Conference, Baltimore, Maryland. See http://www.met.sjsu.edu/faculty/bornstein. bak/urbanization/thermodynamic-URBANIZATION1987.pdf (accessed 15/06/2011).

Brazel A, Fernando H, Hunt JCR, et al. (2005) Evening transition observations in Phoenix, Arizona. USA Journal of Applied Meteorology 44(1): 99-112.

Brewick P, Divel L, Butler K, Bashor R and Kareem A (2009) Consequences of urban aerodynamics and debris impacts in extreme wind events. Proceedings of the 11th Americas Conference on Wind Engineering, San Juan, Puerto Rico. See http://www.nd.edu/ nathaz/doc/Nathaz_Houston_ Document.pdf (accessed 15/06/2011).

Brundtland GH (1987) Our Common Future. Oxford University Press, Oxford, UK.

Canoui-Poitrine F, Cadot E and Spira A (2006) Excess deaths during the August 2003 heat wave in Paris, France. Revue d'Epidemiologie et de Sante Publique 54(2): 127-136.

Cassou C and Guilyardi E (2007) Modes de variabilite et changement climatique. La Meteorologie 59: 22-30.

Cassou C and Terray L (2005) Tropical Atlantic influence on European heat waves. Journal of Climate 18(15): 2805 2811.

CCC (Committee on Climate Change) (2009) Meeting Carbon Budgets - the Need for a Step Change, Progress Report to the UK Parliament, London. See http://hmccc.s3. amazonaws.com $/ 21667 \% 20 \mathrm{CCC} \% 20$ Report $\%$ 20AW\%20WEB.pdf (accessed 15/04/2011).

CCC (2010) How Well Prepared is the UK for Climate Change? See http://downloads.theccc.org.uk.s3.amazonaws.com/ ASC/CCC_ASC_Report_ES_web_1.pdf (accessed 15/04/ 2011).

Clark P, Best M and Porson A (2009) Evolution of urban surface exchange in the UK Met Office's unified model. In Urbanisation of Meteorological and Air Quality Models (Baklanov A, Sue G, Alexander M and Athanassiadou M (eds)). Springer, Berlin, Germany, pp. 62-69.

Collier CG (2007) Flash flood forecasting: What are the limits of predictability? Quarterly Journal of the Royal Meteorological Society 133(622): 3-23.

Crichton D (2007) What can cities do to increase resilience? Philosophical Transactions of the Royal Society A 365(1860): 2731-2740.

Davies M, Steadman JP and Oreszczyn T (2008) Strategies for the modification of the urban climate and the consequent impact on building energy use. Energy Policy 36(12): 45484551. 
DECC (Department of Energy and Climate Change) (2010)

Electricity Market Reform Consultation Document. HMSO, London, UK.

Di Sabatino S, Hedquist B, Carter WL, Leo S and Fernando H (2009) Phoenix urban heat island experiment: effects of built elements. Proceedings of the 8th Symposium on the Urban Environment, Phoenix, Arizona. See www.ams.confex.com/ ams/pdfpapers/147757.pdf (accessed 16/06/2011).

Fenner R (2009) Briefing: Ice, snow and water - impacts of climate change on California and Himalayan Asia. Proceedings of the Institution of Civil Engineers Engineering Sustainability 162(3): 123-126.

Fernando H (2008) Polimetrics: the quantitative study of urban systems (and its applications to atmospheric and hydro environments). Environmental Fluid Mechanics 8(5-6): 1573-1610.

Fernando $\mathrm{H}$, Lee $\mathrm{S}$, Anderson J, et al. (2001) Urban fluid mechanics: air circulation and contaminant dispersion in cities. Journal of Environmental Fluid Mechanics 1(1): 107164.

Gaffen D, Santer B, Boyle J, et al. (2000) Multidecadal changes in the vertical temperature structure of the tropical troposphere. Science 287(5456): 1242-1245.

Gayev Y and Hunt JCR (eds) (2007) Flow and Transport Processes with Complex Obstructions. Springer, The Netherlands.

Harman I and Belcher S (2006) The surface energy balance and boundary-layer over urban street canyons. Quarterly Journal of the Royal Meteorological Society 132(621): 2749-2768.

Head P (2008) Entering the Ecological Age: The Engineer's Role. Institute of Civil Engineering, London, UK, Brunel Lecture Series. See http://www.arup.com/_assets/ _download/72B9BD7D-19BB-316E-40000ADE36037C13. pdf (accessed 16/05/2011).

HEI (Health Effect Institute) (2004) Health Effects of Outdoor Air Pollution in Developing Countries of Asia: A Literature Review. Health Impact Institute, Boston, USA. See http:// pubs.healtheffects.org/view.php?id=3 (accessed 16/05/ 2011).

Hunt JCR (1996) The contribution of meteorology and hydrology to sustaining the environment of large cities. In Habitat II, Dialogue 1: How Cities Will Look in the 21st Century, UNCRD Proceedings Series, Istanbul, Turkey (Goater JF (ed.)). pp. 101-104, see http://www.virtualref. com/uncrd/1038.htm (accessed 10/01/2010).

Hunt JCR (ed.) (2005) London's Environment: Prospects for a Sustainable World City. Imperial College Press, London, UK.

Hunt JCR (2008) Book review on 'Appeal to Reason: a Cool Look at Global Warming' by N. Lawson. Science in Parliament 65(4): 18-19.
Hunt JCR (2009a) Integrated policies for environmental resilience and sustainability. Proceedings of Institute of Civil Engineering, Engineering Sustainability 162(3): 155-167.

Hunt JCR (2009b) Why China needs help cutting its emissions. New Scientist 2720: 22-23.

Hunt JCR and Kopec G (2011) Tsunamis and geophysical warnings. Astronomy and Geophysics 51(5): 5.37-5.38.

Hunt JCR, Orr A, Rottman J and Capon R (2004) Coriolis effects in mesoscale flows with sharp changes in surface conditions. Quarterly Journal of the Royal Meteorological Society 130(603): 2703-2731.

Hunt JCR, Maslin M, Killeen T, Backlund P and Schellnhuber H (2007) Introduction. climate change and urban areas: research dialogue in a policy framework. Philosophical Transactions of the Royal Society A 365(1860): 2615-2629.

Jacobson M (2002) Atmospheric Pollution: History, Science, and Regulation. Cambridge University Press, Cambridge, UK.

Jones A (2004) Sustainability Policies in Woking UK. Evidence to House of Lords. Committee on EU policies on Climate Change. Stationary Office, London, UK.

Kabat P, Fresco L, Marcel S, et al. (2009) Dutch coasts in transition. Nature Geoscience 2(7): 450-452.

Kalkstein A and Sheridan S (2007) The social impacts of the heat-health watch/warning system in Phoenix, Arizona: assessing the perceived risk and response of the public. International Journal of Biometeorology 52(1): 1432-1254.

Kintisch E (2005) Global tsunami warning system takes shape. Science 307(5708): 331.

Lawson N (2008) An Appeal to Reason: a Cool Look at Global Warming. Duckworth, UK.

Lee K (2007) An urbanizing world. In State of the World. (Starke L (ed.)) World Watch Institute, Washington DC, USA, see http://www.worldwatch.org/taxonomy/term/38 (accessed 10/01/2010).

London Climate Change Partnership (2002) The Impacts of Climate Change on London. London Climate Change Partnership, London, UK. See http://www.london.gov.uk/ lccp/publications/im (accessed 23/07/2009).

Lu X, Chow K, Yao T, Lau A and Fung J (2009) Effects of urbanization on the land sea breeze circulation over the Pearl River delta region in winter. International Journal of Climatology 30(7): 1089-1104.

Martin D, Petersson K, White I, et al. (2009) Tracer concentration profiles measured in Central London as part of the REPARTEE Campaign. Atmospheric Chemistry and Physics Discussion 9(6): 25245-25274.

Mathias WR, Fisher B and Piringer M (2002) COST (715) workshop on urban boundary layer parameterization. Bulletin of the American Meteorological Society 83(10): 1501-1504.

Mavrogianni A, Davies M, Batty M, et al. (2011) The comfort, energy and health implications of London's urban heat 
island. Journal of Building Services, Engineering Research and Technology 32(1): 35-52.

Moser S (2007) Is California preparing for sea level rise? California Coast and Ocean 22(4): 24-30.

Netherlands government (2007) Reclaiming the Netherlands from the Future. See http://www.verkeerenwaterstaat.nl/ english/topics/water/water_and_the_future/water_vision/ (accessed 20/10/2009).

Oke T (1978) Boundary Layer Climates. Routledge, London, UK.

Oke T (1982) The energetic basis of the urban heat island. Quarterly Journal of the Royal Meteorological Society 108(455): 1-24.

Orr A, Cresswell D, Marshall J, et al. (2004) A low level explanation for the recent large warming trend over the western Antarctic peninsular involving blocked winds and changes in zonal circulation. Geophysics Research and Letters 31(6): L06204.1-L06204.4.

Orr A, Marshall G, Hunt JCR, et al. (2008). Characteristics of summer airflow over the Antarctic peninsula. Journal of the Atmospheric Sciences 65(4): 1396-1431.

Owinoh A, Hunt JCR, Orr A, et al. (2005) Effects of changing surface heat flux on the atmospheric boundary layer flow over flat terrain. Boundary Layer Meteorology 116(2): 331361.

Pachauri R and Reisinger A (eds) for the IPCC (Intergovernmental Panel on Climate Change) (2007a) Climate Change 2007: Synthesis Report. Contribution of Working Groups I, II and III to the Fourth Assessment Report of the Intergovernmental Panel on Climate Change. IPCC, Geneva, Switzerland. See http://www.ipcc.ch/ publications_and_data/ar4/syr/en/contents.html (accessed 02/02/2010).

Parker D and Penning-Rowsell E (2005) Dealing with disasters. In London's Environment: Prospects for a Sustainable World City (Hunt JCR (ed.)). Imperial College Press, London, UK.

Parry M, Canziani O, Palutikof J, van der Linden P and Hanson C (eds) for the IPCC (2007b) Climate Change 2007: Impacts, Adaptation and Vulnerability. Cambridge University Press, Cambridge, UK.

Plate E (1982) Engineering Meteorology. Elsevier, Amsterdam, The Netherlands.

Porson A, Harman I, Bohnenstengel S and Belcher S (2009) How many facets are needed to represent the surface energy balance in urban areas? Boundary Layer Meteorology 132(1): 107-128.

Ramanathan V, Li F, Ramana M, et al. (2007) Atmospheric brown clouds: hemispherical and regional variations in long-range transport, absorption, and radioactive forcing. Journal of Geophysical Research: Atmospheres 112(D): $22 \mathrm{~S} 21$.

Ravilious K (2010) Blame the volcano trouble on the sun and global warming. New Scientist 19 April 2010, see http:// www.newscientist.com/article/dn18794-blame-the-volcanotrouble-on-sun-and-global-warming.html (accessed 18/03/ 2011).

Ristenpart E (2003) European approaches against diffuse water pollution caused by urban drainage. Proceedings of Diffuse Pollution Conference, Dublin. See http://www.ucd.ie/ dipcon/docs/theme04/theme04_05.PDF (accessed 25/06/ 2008).

Rosenzweig C and Solecki W (2010) New York city adaptation in context. Annals of the New York Academy of Sciences 1196(1): 19-28.

Rosenzweig C, Solecki W, Hammer SA and Mehrotra S (2010) Cities lead the way in climate-change action. Nature 467(7318): 909-911.

Rotunno R (1983) On the linear theory of the land- and seabreeze. Journal of Atmospheric Science 41(8): 1999-2009.

Schellnhuber HJ, Crutzen PJ, Clark WC, Claussen M and Held H (eds.) (2004) Earth System Analysis for Sustainability. MIT Press, Cambridge, USA.

Smith T, Yin X and Gruber A (2006) Variations in annual global precipitation (1979-2004) based on the global precipitation climatology project 2.5 analyses. Geophysical Research Letters 33(L): 06705.

Stern N (2007) The Economics of Climate Change. The Stern Review. Cambridge University Press, Cambridge, UK.

Tang X (2006) Managing disaster risk in a mega-city. WMO Bulletin 55(4): 268-272. See http://www.wmo.int/pages/ prog/www/WIS/Publications/Bulletin55_4.pdf (accessed 15/ 11/2011).

Tyndall Centre for Climate Change Research (2010) Four Degrees and Beyond. Tyndall Centre for Climate Change Research, University of East Anglia, Norwich, UK, Special Issue. See http://www.tyndall.ac.uk/communication/news-archive/ 2010/four-degrees-and-beyond-special-issue-journal$\%$ E2\%80\%93-tyndall-centre-bring (accessed 01/02/2011).

UK Planning Act (2008). Her Majesty's Stationery Office, London, UK.

UN (United Nations) (1992) Convention on Biological Diversity. See http://www.cbd.int/ (accessed 01/10/2010).

UN (1996) United Nations Conference on Human Settlements. The Habitat Agenda, Istanbul.

UN (2001) World Urbanization Prospects: The 2001 Revision. See http://www.un.org/esa/population/publications/ wup2001/WUP2001_CH6.pdf (accessed 01/01/2011).

UN Population Division (2006) World Urbanisation Prospects: The 2005 Revision. Executive Summary, Fact Sheets, Data Tables. UN, Department of Economic and Social Affairs, New York, USA.

UNEPFI (United Nations Environment Programme Finance Initiative) (2009) The Global State of Sustainable Insurance. Report by the Insurance Working Group of the United Nations Environment Programme Finance Initiative. See 
http://www.unepfi.org/fileadmin/documents/global-stateof-sustainable-insurance_01.pdf (accessed 01/10/2010).

Zilitinkevich SS, Hunt JCR, Esau IN, et al. (2006) The influence of large convective eddies on the surface layer turbulence. Quarterly Journal of Royal Meteorological Society 132(618): 1423-1456.

\section{WHAT DO YOU THINK?}

To discuss this paper, please email up to 500 words to the editor at journals@ice.org.uk. Your contribution will be forwarded to the author(s) for a reply and, if considered appropriate by the editorial panel, will be published as discussion in a future issue of the journal.

Proceedings journals rely entirely on contributions sent in by civil engineering professionals, academics and students. Papers should be 2000-5000 words long (briefing papers should be 1000-2000 words long), with adequate illustrations and references. You can submit your paper online via www.icevirtuallibrary.com/content/journals, where you will also find detailed author guidelines. 